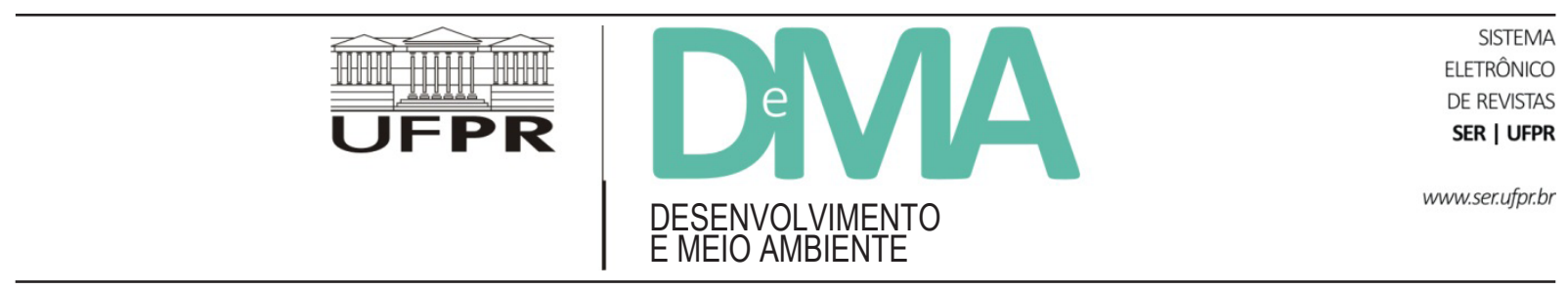

\title{
Editorial
}

\section{A importância do conhecimento científico para o aprimoramento do Licenciamento e da Avaliação de Impacto Ambiental no Brasil}

\section{The Importance of Scientific Knowledge in Improving Environmental Licensing and Impact Assessment in Brazil}

O Licenciamento Ambiental e a Avaliação de Impacto Ambiental (AIA) tornaram-se, em poucas décadas, protagonistas da política ambiental brasileira. Esses dois instrumentos têm sido cada vez mais utilizados para prevenir, mitigar e compensar os impactos negativos de empreendimentos no meio ambiente e nas comunidades onde estão inseridos. As abordagens de implantação também se diversificaram. Até o início da década de 1990, os dois instrumentos eram utilizados pela União e pelos estados quase que exclusivamente de maneira vinculada, seguindo o rito trifásico da Licença Prévia (LP), Licença de Instalação (LI) e Licença de Operação (LO) subsidiadas, quando houvesse a perspectiva de ocorrência de degradação ambiental significativa, do Estudo de Impacto Ambiental (EIA) e do seu respectivo Relatório de Impacto Ambiental (RIMA). Mas o aprendizado com a crescente implementação e regulação dos instrumentos estimulou o surgimento de novos formatos: emissões concomitantes de LP, LI e LO, criação de estudos simplificados, procedimentos on-line, avaliações ambientais estratégicas, licenciamentos ambientais municipais, licenças autodeclaratórias...

A disseminação e a diversificação do Licenciamento Ambiental e da AIA têm contribuído para a mitigação dos efeitos negativos e para o aprimoramento dos atributos sociais e ambientais de projetos e propostas de desenvolvimento. Todavia, esses benefícios, no Brasil e em diversos países, não costumam ser monitorados, mensurados e, portanto, percebidos pela sociedade (Sánchez, 2013; Morrison-Saunders et al., 2015). Por esse e outros motivos, são os problemas desses instrumentos (e.g. morosidade, judicialização, conflitos, qualidade técnica etc.) que geralmente ganham destaque na mídia e provocam debates. Nos últimos anos, a visibilidade desses problemas aumentou significativamente. Organizações influentes, como o Banco Mundial, a Confederação Nacional das Indústrias (CNI) e a Associação Brasileira de Entidades Estaduais de Meio Ambiente (ABEMA), dentre outras, 
publicaram relatórios que, além de destacar as fragilidades dos instrumentos, sugeriam maneiras de superá-las (Banco Mundial, 2008; ABEMA, 2013; CNI, 2013). Em reação, ganharam força no Congresso Nacional e no Conselho Nacional de Meio Ambiente (CONAMA) alguns projetos de lei e propostas de normas que pretendem reformar, em profundidade, todo o sistema de licenciamento (Fonseca et al., 2017).

Organizações da sociedade civil e pesquisadores começaram a se posicionar nesse debate. No final de 2016, mais de 120 ONGs e associações sem fins lucrativos assinaram uma Nota de Repúdio contra uma das versões do Projeto de Lei 3.729/2004, que pretende instaurar a Lei Geral do Licenciamento Ambiental. De acordo com a nota, a "aprovação da referida proposta, ainda mais sem os imprescindíveis debates públicos, geraria inúmeras consequências negativas, como o significativo aumento de risco de ocorrência de desastres socioambientais [...]" e acabaria ampliando "[...] conflitos sociais e socioambientais e a absoluta insegurança jurídica aos empreendedores e ao Poder Público" (Nota de Repúdio, 2016). Na opinião de Bragagnolo et al. (2017), esse e outros projetos de lei estão sendo fortemente influenciados por grupos ruralistas e industriais, que parecem estar mais preocupados em avançar suas agendas setoriais do que em resolver as barreiras políticas, técnicas e orçamentárias que historicamente comprometem a eficiência do licenciamento e da avaliação de impacto no Brasil. Para lidar com essa ânsia de mudança em um contexto de pluralidade de visões, como salientou Fearnside (2016, p. 748), "é crítico que a comunidade científica faça contribuições contínuas, de modo a guiar as políticas ambientais brasileiras para um futuro melhor"."

Nunca esteve tão patente a importância do conhecimento científico para o aprimoramento do Licenciamento e da AIA no Brasil. Poucos discordam que esses instrumentos têm problemas; a divergência reside em "como" resolvê-los, sem retroceder em seus valores fundamentais conquistados pela sociedade brasileira nas últimas três décadas. O processo de Licenciamento e de Avaliação de Impacto Ambiental contempla várias etapas (e.g. triagem, escopo, avaliações, consultas públicas, decisão, acompanhamento, etc.) que podem ser operacionalizadas de diversas maneiras. Além disso, esse processo está inerentemente conectado a outros instrumentos de política ambiental de âmbito público e privado, como: zoneamento ambiental, planos de bacia hidrográfica/recursos hídricos, sistemas de informação, planejamentos plurianuais e incentivos econômicos, bem como instrumentos corporativos de responsabilidade social e gestão ambiental. Essas complicadas arestas internas e externas do Licenciamento e da AIA dificultam o consenso. As soluções não são simples. Promover mudanças calcadas em retórica, mas sem embasamento empírico e factual, é um risco a ser evitado. Nesse contexto, a comunidade científica e demais grupos de praticantes precisam ser ouvidos.

A produção e a difusão de conhecimento sobre o Licenciamento Ambiental e AIA no território brasileiro, ainda que tenham apresentado consideráveis avanços nos últimos anos, ainda se posicionam em um patamar aquém de seu "potencial instalado". O país ainda não conta com periódicos dedicados exclusivamente a essa temática, como acontece

\footnotetext{
1 Tradução dos autores do inglês, cujo original é: "Continued input from the scientific community is critical to guide environmental policy toward a better future in Brazil."
} 
internacionalmente ${ }^{2}$. As pesquisas brasileiras têm sido divulgadas em periódicos de diversas áreas do conhecimento, fato que foi corroborado por Duarte et al. (2017) em uma recente revisão sistemática da produção brasileira publicada em periódicos científicos. Esses autores identificaram 131 artigos sobre Licenciamento e AIA publicados no período de 1985 a 2015, os quais, apesar de tratarem de diversos temas, não contemplavam todas as questões que estão sendo e/ou precisam ser debatidas. Existe, pois, uma clara demanda por mais pesquisas nessa área. Os avanços em relação a essa demanda, como enfatizaram Montaño \& Souza (2015), são dificultados por diversas barreiras; dentre essas, destaca-se a falta de um campo de ensino e pesquisa estruturado e emancipado, que seja reconhecido por agências de fomentos de pesquisa e que contribua para minimizar a persistente lacuna existente entre pesquisa e prática.

O conhecimento técnico e científico que tem sido gerado em diversas instituições brasileiras precisa alcançar aqueles que estão à frente das mudanças dos regulamentos e procedimentos de licenciamento ambiental e AIA. Foi pensando nisso que a Associação Brasileira de Avaliação de Impacto (ABAI) criou o Congresso Brasileiro de Avaliação de Impacto (CBAI): um evento bianual que reúne profissionais de meio ambiente, consultores, representantes de órgãos ambientais, acadêmicos e sociedade civil para debater os meios de aperfeiçoar os processos de tomada de decisões no âmbito do licenciamento e da AIA. Ao longo de suas três edições (2012, 2014 e 2016), foram apresentados no CBAI centenas de trabalhos científicos, dos quais quase 300 foram publicados em formato completo nos respectivos anais (ABAI, 2017).
Esta edição especial da revista Desenvolvimento e Meio Ambiente traz exemplos de alguns dos melhores trabalhos apresentados no $3^{\circ} \mathrm{CBAI}$. Os nove artigos que integram essa edição, desenvolvidos a partir de trabalhos apresentados no congresso, foram expandidos, avaliados por pares e revisados, e espelham em grande medida a amplitude de abordagens e temas predominantes na pesquisa sobre AIA realizada no Brasil.

$\mathrm{O}$ artigo de Veronez e Montaño sobre a qualidade do conteúdo dos EIAs que subsidiam o Licenciamento Ambiental no Espírito Santo, que abre essa edição, é um bom exemplo. Os autores tratam de um tema que, apesar de ser muito discutido no Brasil, raramente é avaliado com base em métodos internacionalmente aceitos, de modo a possibilitar a confrontação dos resultados com outros países. Ao utilizar o modelo Lee and Colley Review Package, os autores não apenas mostraram os pontos fracos e fortes dos estudos, mas viabilizaram interessantes comparações com estudos sobre qualidade de EIAs já realizados na Europa e em países com tradição em pesquisa sobre AIA, como Austrália e Canadá.

$\mathrm{O}$ artigo de Gallardo, Silva, Gaudereto e Sozinho tratou de um tema que, assim como a qualidade de EIAs, também se integra ao debate corrente na literatura internacional: a avaliação de impactos cumulativos. E o fez também à luz de boas práticas internacionais, mas com um foco no planejamento ambiental de hidrelétricas na Amazônia. O estudo evidenciou que os efeitos cumulativos, apesar de relevantes para as tomadas de decisão, raramente são devidamente considerados, devido a fatores de ordem técnica e política que dificultam a identificação de informações por meio de diferentes escalas e meios.

\footnotetext{
2 Por exemplo: Environmental Impact Assessment Review (Elsevier), Impact Assessment and Project Appraisal (Taylor \& Francis), Journal of Environmental Assessment Policy and Management (World Scientific).
} 
Gomes e Silva trataram do Licenciamento no setor hidrelétrico por meio da lente do conflito. Ao avaliar os conflitos que emergiram em três casos de Licenciamento Ambiental de Pequenas Centrais Hidrelétricas no Paraná, os autores identificaram significativas limitações do licenciamento, que superam os aspectos positivos verificados, e concluem que a prática atual do Licenciamento não captura as complexas dinâmicas formal e informal que permeiam os conflitos em torno desta tipologia de projetos.

Os desafios ao Licenciamento Ambiental também ficaram evidenciados no artigo de Fernandes, Guimarães e Almeida, que analisou a consideração de alternativas nos EIA/RIMAs elaborados para projetos de rodovias no Estado de Minas Gerais. Com base em uma lista de verificação inspirada em diversas fontes, os autores evidenciaram uma série de aspectos comuns que devem ser evitados durante a elaboração dos estudos de alternativas, o que possibilita a identificação de caminhos para o aperfeiçoamento dos estudos de impacto ambiental.

Tendências de incorporação do conceito de serviços ecossistêmicos na AIA foram fortemente representadas nesta edição. Dois artigos, o de Septanil, Pinto e Campanhão e o de Longo e Rodrigues, trataram do tema. Este último adotou um método mais focado e aplicado, no qual se avaliou a interação entre os impactos de um empreendimento minerário com os serviços ecossistêmicos ofertados. Já o artigo de Septanil, Pinto e Campanhão avaliou o grau de consideração do conceito de serviços ecossistêmicos em 110 EIAs coletados em processos de AIA no Estado de São Paulo. Para tal, as autoras propõem a adoção de um índice de análise com potencial de ser replicado em outros contextos.

A importância da articulação entre o planejamento ambiental-territorial e o Licenciamento Ambiental também foi objeto de discussão nesta edição especial. O artigo de Santos avalia a articulação dos zoneamentos ecológico-econômicos elaborados no Brasil e dos planos diretores municipais com o Licenciamento Ambiental. Os resultados evidenciam um baixo nível de articulação e levantam outras questões a serem consideradas para o fortalecimento do planejamento ambiental.

A participação pública, tema central da edição de 2016 do CBAI, foi tratada no artigo de Faria e Silva, que foram além das "tradicionais" análises de audiências públicas e avançaram nas análises de outras formas de participação, tais como publicações em jornais, consultas prévias, referendos populares, etc. Apesar de os autores terem obtido dados empíricos em casos ocorridos no Estado do Espírito Santo, os resultados e as discussões podem ser úteis em diversas jurisdições.

Finalmente, o artigo de Nascimento e Fonseca contribui com um levantamento panorâmico do crescente fenômeno da municipalização do Licenciamento Ambiental no Brasil. Uma survey nacional evidenciou o estado da arte da municipalização a partir da ótica daqueles que coordenam (gestores públicos) e utilizam (empreendedores e consultores) o Licenciamento Ambiental no município. Os resultados corroboram as preocupações com a questão da capacidade institucional local e levantam outras questões até então marginalizadas.

Esta edição especial é rica e diversa. Esperamos que ela possa reverberar o chamado de Fearnside (2016) e estimular a produção contínua de conhecimento sobre a temática do Licenciamento Ambiental e da AIA, fortalecendo os debates e contribuindo para a melhoria da qualidade socioambiental do território brasileiro.

Alberto Fonseca Marcelo Montaño Evandro Moretto Organizadores 


\section{Agradecimentos}

Agradecemos à diretoria e aos associados da ABAI, à comissão científica do CBAI de 2016 e aos revisores que contribuíram para essa edição. Também agradecemos aos editores da revista $D e-$

\section{Referências}

ABAI. Conhecimento - Publicações da ABAI, 2017. Disponível em: $<$ http://avaliacaodeimpacto.org.br/wp-content/ uploads/2015/04/AnaisCBAI2014searchable.pdf $>$. Acesso em: 22 nov. 2017.

ABEMA. Novas propostas para o licenciamento ambiental no Brasil. Brasília: Associação Brasileira de Entidades Estaduais de Meio Ambiente (ABEMA), 2013.

Banco Mundial. Licenciamento Ambiental de Empreendimentos Hidrelétricos no Brasil: uma contribuição para o debate. Brasília: Banco Mundial, 2008.

Bragagnolo, C.; Carvalho Lemos, C.; Ladle, R. J.; Pellin, A. Streamlining or sidestepping? Political pressure to revise environmental licensing and EIA in Brazil. Environmental Impact Assessment Review, 65, 86-90, 2017.

CNI. Proposta da indústria para o aprimoramento do Licenciamento Ambiental. Brasília: Confederação Nacional da Indústria (CNI), 2013.

Duarte, C. G.; Dibo, A. P. A.; Sánchez, L. E. What does the academic research say about impact assessment and environmental licensing in Brazil? Ambiente \& Sociedade, 20(1), 261-292, 2017. senvolvimento e Meio Ambiente, que perceberam a importância desta colaboração e viabilizaram uma edição especial que tem o potencial de se tornar um marco na literatura brasileira sobre avaliação de impacto.

Fearnside, P. M. Brazilian politics threaten environmental policies: the country's environmental licensing system is threatened. Science, 363(6301), 746-748, 2016.

Fonseca, A.; Sánchez, L. E.; Ribeiro, J. C. J. Reforming EIA systems: A critical review of proposals in Brazil. Environmental Impact Assessment Review, 62, 90-97, 2017.

Montaño, M.; Souza, M. P. D. Impact assessment research in Brazil: achievements, gaps and future directions. Journal of Environmental Assessment Policy and Management, 17(1), 1550009-1550001-1550009-1550008, 2015.

Morrison-Saunders, A.; Bond, A.; Pope, J.; Retief, F. Demonstrating the benefits of impact assessment for proponents. Impact Assessment and Project Appraisal, 33(2), 108-115, 2015.

Nota de Repúdio. Nota de Repúdio ao substitutivo do Deputado Mauro Pereira ao Projeto de Lei n. ${ }^{\circ} 3.729 / 2004$, 2016. Disponível em: $<$ https://www.icv.org.br/wp-content/ uploads/2016/12/Nota-Rep\%C3\%BAdio.pdf $>$. Acesso em: 11 nov. 2017.

Sánchez, L. E. Development of Environmental Impact Assessment in Brazil. UVP Report, 27, 193-200, 2013. 